\title{
The Use of Location Specific Advertisements on Facebook: Can they Help Entrepreneurs Solve Problems Associated with Banner Advertisements?
}

\section{Frank Martin}

The Management School, University of Stirling Stirling, UK

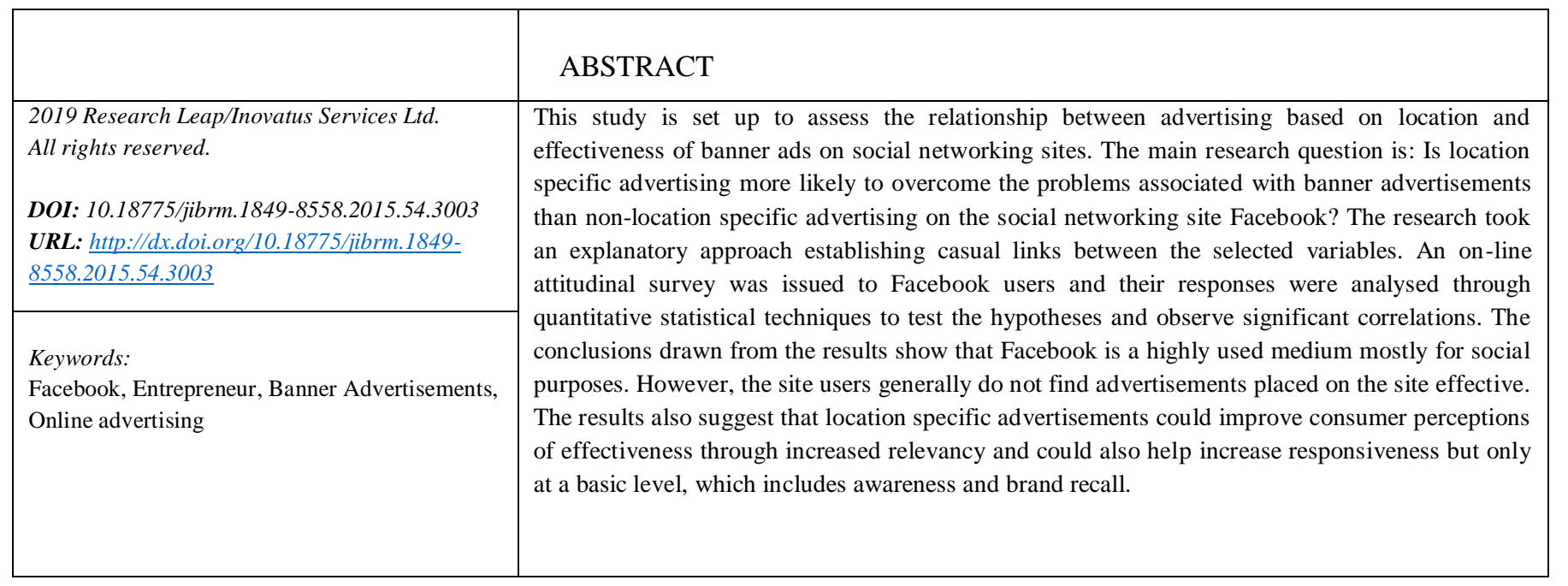

\section{Introduction}

Generally, the Internet and associated technologies is of great importance to entrepreneurs and international businesses. It is a low cost route to international markets (Jobber, 2004), which can bring down industry barriers for smaller firms (Doyle \& Stern, 2006; Belch \& Belch, 2004). The focus here is on the use of Internet advertising and in particular, banner advertisements, which are the simplest and most common form of on-line advertisement but their effectiveness is questionable (Belch \& Belch, 2004; Chaffey, 2003). Online advertising is of particular relevance to international business because consumers can be easily made aware of products globally and buy directly online.

However, businesses also often face the dilemma of choosing the right solution and how globalised or localised their approach to advertising should be. International marketing online involves the problem that an increasing number of customers have access to the same information and it is harder to tailor it to local markets (Belch \& Belch, 2004). Cullen \& Parboteeah (2005) warn that firms operating internationally must still solve the global-local dilemma. Additionally, banner advertisements, often placed on social networking sites, are widely criticised for their lack of effectiveness with a click through rate as low as $0.5 \%$ but there is the possibility that this could be counteracted through an increasing relevancy to the consumer. A major problem with banner ads is that there are so many of them and the resulting clutter has a detrimental effect on effectiveness. Indeed, the popularity of social networking sites is one of the reasons Kennerdale (2001) identifies for the failure of banner ads is they are often untargeted despite the Internet offering opportunity for targeting a particular audience. E-Marketer (15/2/2009) predicts that usage of social network sites will continue to grow and that the involvement level of existing users is deepening. They also claim that the demographic range of social network users is expanding. Social networking sites are particularly helpful for online targeted marketing campaigns because they are full of personal data that people voluntarily or accidentally offer. One of the key strengths social network sites hold for advertisers is the large amount of time people are spending on these sites. Yet marketers are increasingly puzzled about their effectiveness mainly because of the social aspect of these sites where people 'come' to socialise but not to purchase (Economist, 27/11/2008).

This paper will look at the relationship between advertising based on location and effectiveness of banner ads on social networking sites. Location will be used due to the global-local dilemma businesses face. Specifically, the research question is 
as follows. Is location specific advertising more likely to overcome the problems associated with banner advertisements than non-location specific advertising on social networking sites such as Facebook?

The research took an explanatory approach establishing casual links between the selected variables. An on-line attitudinal survey was issued to Facebook users and their responses were analysed through quantitative statistical techniques to test the hypotheses and observe significant correlations. The study focused on only one social networking site, the Facebook, one of the most popular sites of this kind. In March 2009 Facebook overtook e-mail as the most popular communication tool (James, 2009). Facebook now claim that advertisers can reach an audience of over 200 million active users (Facebook.Com, 2009). Similar to the social networking industry as a whole, the demographic reach is increasing for Facebook. For instance, the audience is getting older with $46 \%$ of users being over 26 years of age (E- Marketer, 25/02/2009). For these reasons Facebook was chosen as the empirical research context for our study of the effectiveness of social network advertising.

\section{Literature Review}

There is a global on-line culture with everyone being able to access the same information and this makes it difficult to tailor messages to different local markets (Belch \& Belch, 2004). To do this effectively companies must solve what is known as the global-local dilemma (Cullen \& Parboteeah, 2005). On-line consumer marketing often presents companies with the problem of wanting to be a global organisation with shared values and modes of operation but they also need to be attentive the culture of local markets they are trying to target (Oz, 2002). Global approaches are more standardised and can offer standardised communications. Localised approaches are more attentive to cultural diversity and the differing needs of different populations. A localised approach will go beyond translation and adapt to cultural, technical and administrative differences (Tixier, 2005). The term "glocalisation" refers to the use of a combination of the two approaches $(\mathrm{Oz}, 2002)$. For example, the United Airlines site

for France has the same structure as the American site but offers services and content specific to the needs of the French consumer (Tixier, 2005). Advertisers may find their on-line campaigns more effective if they take this more localised approach.

\section{On-Line Advertising}

On-line advertising expenditure has exploded and many leading brands have launched on-line campaigns (Krishnamurphy, 2000). This has accompanied changes to how consumers use different forms of media. Over $20 \%$ of consumers in the UK, Germany, the US and Japan and 33\% of consumers in France and Italy say they watch less television now that they have Internet access.
Some of the factors making on-line advertising popular include the proportion of the target segment that can be reached compared to traditional media, the proportion researching offerings on-line and the proportion willing to make a purchase on-line (Chaffey, 2007). The ease of reaching huge numbers has also meant small companies can reach audiences they could never reach before on their limited marketing budgets (Belch \& Belch, 2004).

The Internet offers many other features attractive to advertisers. In particular, there is the ability to target audiences specifically with a tailored message reducing wastage (Belch \& Belch, 2004; Chaffey, 2007; Krishnamurphy, 2000). There are also instances where direct relationships are developing between consumer and producer (Sharma \& Sheth, 2002). Interactivity can provide a greater chance of communicating a powerful message to the target group (Chaffey, 2003). However, some forms of on-line advertisements may not be effective at enabling these benefits for instance banner advertisements have to grab the users' attention before any kind of interactivity can take place.

Traditional media, such as television, offers the same message to different segments as it is often poorly targeted (although media fragmentation does allow for some targeting). Often consumers would not even watch the advertisements; instead they would find another way to fill the time, such as channel hopping. The Internet is a lean forward media, meaning it tends to have the user's full attention, unlike television that could simply be on in the background (Chaffey, 2007). This would make it of interest to marketers to utilise the benefits of the Internet as an advertising medium. However, although the site being visited is likely to have a user's full attention, this does not guarantee that any advertisement will receive any of the users' attention.

\subsection{Social Networking Sites and On-Line Advertising}

The demographic coverage of social networking sites makes them attractive to an international marketer. A growing number of people use social networking sites, including the hard to reach group of 18-26 year olds (Whiteside, 2008). These sites have seen a rapid increase in usage while traffic to other on-line media such as portals has decreased (James, 2009). Within Europe, 210 million people visit social networking sites in a month (E- Marketer, 19/03/2009). This usage is increasing. In the US alone it is predicted that the number of users will increase by $44.2 \%$ to 115 million (E-Marketer, 17/02/2009).

Social networking sites allow marketers to identify and target their audience more easily (Aitchison, 2006). Therefore, in theory, advertisers should be able to offer high impact messages with minimal wastage through more effective targeting (Grande, 2009). Commonalities, on which targeting can be based, can include race, religion, sexuality, hobbies, interests, abilities, location and numerous other factors (Hawkes \& 
Gibbon, 2008). To reach the target audience effectively advertisers need to identify the most relevant sites and who uses them. The target audience should be known and where their 'hot spots' are, as this is where they are likely to be more receptive to the brand message (Hawkes \& Gibbon, 2008).

One of the strengths of social networking sites is the amount of time spent on them by users. According to Whiteside (2008), $87 \%$ of users visit at least once a week and $30 \%$ visit every day. This is important to the notion that social networking sites provide a useful tool for advertisers and leads to the first hypothesis:

Hypothesis 1: Facebook will be a highly used medium by respondents.

According to James (2009) "the opportunity is there and is bigger than the problem." Social networking sites present advertisers with many opportunities but if banner advertisements are the format of choice it may be possible, as there are many problems associated with on-line banner advertisements, that the problem is actually bigger than the opportunity.

\subsection{On-Line Banner Advertisements and Their Problems}

According to Chaffey (2003), the purpose of the banner advertisement is to direct traffic to the website where advertisers want the consumer to click on the link. A banner advertisement can therefore be considered an "ad for the ad" as it is an advertisement for the website, which is the actual advertisement for the offering (Choi \& Rifon, 2002). They will also be hoping that an advertising message will be seen either consciously or subconsciously (Chaffey, 2003). If we agree with Chaffey's definition for the purpose of banner advertisements, then it must be said that the effectiveness of banner advertisements has increasingly declined over the past decade. The click through rate started at 7\% in 1996 but has declined to between only $0.2 \%$ and $0.3 \%$ only (Chaffey (2007).

Part of the reason why banner advertisements are losing effectiveness is due to clutter (Belch \& Belch, 2004), they are everywhere and do not stand out (Kennerdale, 2001). Consumers often ignore anything that looks like an advertisement on a web page (Chaffey, 2007) as the purpose of their visit will not be to view a banner advertisement. Some researchers observed eye movements of consumers as they browsed web pages and found that they not only gave them little attention but actually actively avoided them (Krishnamurphy, 2000; Dreze \& Hussher, 1999). On top of this, they can often be poorly targeted with no cultural, geographical or industrial relevance (Kennerdale, 2001).

These are the main problems associated with on-line banner advertisements but an important criticism has not been made of the literature so far. This is related to the use click through rates as a measure of effectiveness. If more traditional marketing tools are used, banner advertisements may not seem as ineffective. Choi \& Riffon (2002) argue that they can have a positive effect on brand awareness, attitudes and purchase intention as well as web traffic. Some researchers believe that banner advertisements should be used at a more basic level by suggesting that advertising budgets are better spent on building awareness, not brand building. (Ilfeld \& Winer, 2001).

The Hierarchy of Effects model is the best known and is commonly used to assess the effectiveness of marketing communications. It reflects the stages the consumer goes through to eventually make a purchase. There is also the Innovation Adoption model, which refers to the stages a consumer goes through when adopting a new product, and the Information Processing model, which unlike the other models includes retention (Belch \& Belch, 2004). A combination of the models that could be used to assess effectiveness at different levels of response is shown as Figure 1.

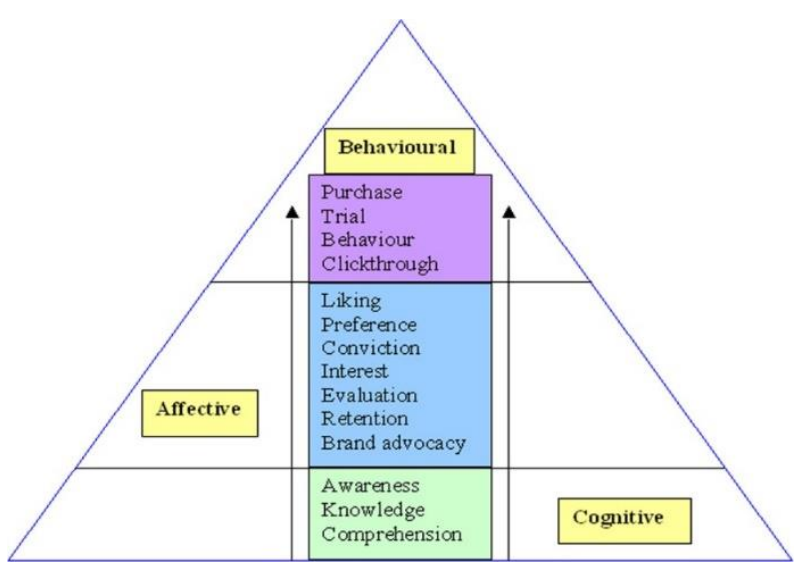

Figure 1: On-line Consumer Response Hierarchy Source: Belch \& Belch, 2004: 147-148

\subsection{Banner Advertisements On Social Networking Sites}

High status vehicles such as Facebook tend to be more effective at creating a positive advertising effect (Choi \& Rifon). Despite this, there have been relatively few examples of successful social media marketing (Grande, 2009). Many advertisers consider it to be an unproven medium and think the semicontrolled environment poses a risk to the brand (James, 2009; Vogt \& Knapman, 2008). It is also a fickle market with consumers always moving to the next 'hotspot' (Raskin, 2006).

To highlight the problem of advertising on a social space, Ted McConnell, General Manager of Interactive Marketing for Procter \& Gamble was quoted as saying (Tamler, 2009) "What on earth made you think you could monetise the real estate in which somebody is breaking up with their girlfriend?"

Social networking sites such as Facebook fit into this category. On-line, the control lies with the consumer so it is more important than ever to understand things from their vantage 
point. For example, are they on-line to shop, socialise or for entertainment? The research will therefore test the following hypothesis:

\section{Hypothesis 2(a): Respondents will use social networking sites mainly for social purposes}

The purpose of social networking sites may make them ineffective hosts for banner advertisements. On-line, users will intentionally seek information relevant to their needs (Choi \& Rifon, 2002). However, it is possible to switch motives, for example, if the user becomes bored with the original motive or something else grabs their attention (Rogers \& Thorson, 2000). In order to do this, it is important for the advertising message to stand out. The problems associated with the environment and motives for visiting the site combined with the problems associated with on-line banner advertisements leads to the following hypothesis:

Hypothesis 2(b): Respondents will not find banner advertisements placed on social networking sites effective

A UK study by Jam/Myspace in early 2009 showed that $26 \%$ of social media users felt bombarded by too much clutter and advertising (James, 2009). They want to choose how and where they digest advertising messages (Hawkes \& Gibbon, 2008). Clutter is a problem but there are still arguments that marketers can break through it with well targeted messages. It is therefore worthwhile investigating whether forms of targeted marketing can break through the clutter, as the literature does not provide a clear answer to this question.

Marketers have to find ways of overcoming these problems. One way is to make the advertising message as relevant as possible to the recipient. Segmentation and targeting will therefore prove to be important. One of the ways consumers can be segmented is be geographic location. The use of location specific advertising may be able to grab the attention of the target market through increased relevance to the consumer.

\subsection{Localization of Advertisements}

In theory, users will be more responsive to advertisements that fit their profile (Kennerdale, 2001). Customers want to experience responsiveness to their needs and first impressions are important (Chaffey, 2007). Messages must be relevant to the target audience. An example of a poorly targeted banner advertisement on Facebook is that for the Give Blood campaign. The advertisement was posted on the profile pages of Scottish members and provided a link taking the respondent to a website where they could find out where to donate blood (Facebook.com). However, the website only provided locations within England and Wales, Give Blood in Scotland had an entirely different website. This was an example of poor geographical targeting because it meant the respondent had to take extra steps to find the information they needed, which reduces the chances of the respondent actually seeking the information.

Cultural differences that are often ignored in the context of social networking sites may significantly affect the effectiveness of this new advertising channel (Hawkes \& Gibbon, 2008). For example, UK audiences are less tolerant to intrusive advertisements than US audiences, suggesting certain types of advertisements can be used in some countries but not in others (Kennerdale, 2001). It is therefore important that advertisers acknowledge the differences between countries. Ignorance of culture differences on social networking sites may create embarrassment and make communication ineffective. Tixier (2005) claims that localisation can lead to a $200 \%$ increase in e-sales for an organisation operating outside of its own language borders. This leads to the final hypothesis, which has been broken into two parts:

\section{Hypothesis 3(a): Respondents will have a more positive attitude towards location specific advertisements on Facebook}

Hypothesis 3(b): Respondents will be more responsive to location specific advertisements on the social networking site

Existing scholarly literature on the use of location specific advertisements on social networking sites is with isolated cases, scarce and not well empirically supported. Unni \& Harmon (2007) have provided research on the use of location-based advertisements. 1 The benefits of using this form of advertising are being able to reach the consumer when they are ready to buy and to provide a message within an appropriate context. Promotions can be offered for preferred products or services relevant to the consumer's location (Unni \& Harmon, 2007). Even so, Unni \& Harmon's (2007) research shows that the perceived benefits of location based advertising to be low and it only seemed to be relevant to consumers when they actively requested the information.

It would seem, judging from the banner advertisements placed on Facebook pages, that location specific advertisements still have their place. It is common for international music acts to announce their tour in a particular country. For example, the American singer Taylor Swift posted banner advertisements on the Facebook profile pages of UK users that provided a link to a website with venues and dates, a video advertisement for the tour and the opportunity to buy tickets from the site.

\section{Research Method}

Measuring the Effectiveness of On-line Advertisements is one of the greatest challenges regarding banner advertisements and deters many advertisers from using the medium (Krishnamurphy, 2000). Social network sites are no exception. Attitudinal measures are important as research suggests exposure to banner advertisements can have effects such as increased awareness, recall and positive attitudes even when 
there has been no click through (Krishnamurphy, 2000; Rogers \& Thorson, 2000; Dreze \& Hussher, 1999). These issues have had an influence on the choice of the research method used. Our research takes an explanatory approach establishing casual links between selected variables: location specific content in the written text of banner advertisements (independent variable), consumer responsiveness to the advertisement and consumer attitudes to the brand (dependent variables), and extraneous variables related to, for example, emotional appeal. The extraneous variables make it difficult to measure by experiment as there are factors that could influence an individual's response. For this reason, the opinion of the respondents is being asked directly, rather than observed. The dependent variables being researched are therefore opinion based.

The survey was conducted on-line in the first half of 2009. The questionnaire was constructed around the key research objectives with each section of the questionnaire geared at answering one of the research objectives. The questionnaire was made up of categorical options for the respondents to choose from. For the questions geared at obtaining the respondent's opinion a list of statements was presented using the Likert-style rating scale. Different forms and levels of responsiveness were identified using the On-line Consumer Response Hierarchy presented earlier as Figure 1.

Points of contact on Facebook were used to distribute the questionnaire. The points of contact were about 1,000 international students on several University campuses across the UK, mainly from within the hard to reach age group of 1826 years of age and with the additional aim of identifying possible cultural differences. We received 176 useable replies representing $17.6 \%$ of the sample.

Basic descriptive analysis of the data collected was carried out to see where the majority of the responses tended to be positioned. This was then teamed with statistical analysis using the Spearmans Rho test. As many of the variables used were ordinal (categorical variable with some form of intrinsic ranking) non-parametric measures were employed. The correlation coefficient was used to assess the strength of the linear association between pairs of ordinal variables, which included questions where respondents were asked to indicate strongly agree, agree, neutral, disagree or strongly disagree.

The sample was quite varied in terms of nationality, 22 in total, however the majority were from the UK $(52.99 \%)$ followed by China (7.46\%), India (4.48\%), Nigeria (4.48\%), North America $(4.25 \%)$, Germany $(3.73 \%)$ as the main nationality groups. The age distribution was made of two dominant bracket groups, 20$26(57.45 \%)$ and $27-34(31.34 \%)$. The remaining were mature students, anything between 35 and 53 years of age.

\section{Results and Discussion}

The results for each section, geared at testing each hypothesis, are now discussed in relation to the literature review. Although not every result can be covered in this section, the results most relevant to answering the research questions have been discussed.

\section{Hypothesis 1: Facebook will be a highly used medium by respondents}

The survey confirms that Facebook is the most (90.75\%) used social network site. The majority of the respondents $(59.54 \%)$ visit the site every day and only $9.83 \%$ visit it less than once a week, $10.4 \%$ visit every other day, $15.03 \%$ couple of times per week, once a week $5.20 \%$. The results show that $38.73 \%$ of the respondents tend to spend 10-19 minutes on the site per visit, $17.92 \%$ spend $20-29$ minutes and $11.56 \%$ spend $30-39$ minutes. This suggests that the most people do spend an amount of time looking at the site, although not a massive amount of time with only $1.16 \%$ spending $40-49$ minutes on the site and $7.51 \%$ spending over an hour on the site. There are still a large percentage of respondents who do not spend much time on the site with $23.12 \%$ spending less than 10 minutes per visit.

Whiteside's (2008) claims that people are watching less television and moving onto the Internet. Internet users can visit many sites when on-line. Is Facebook a highly used site? The results say yes.

Facebook is a highly used medium by respondents as the large majority $(91 \%)$ say it is the social networking site they visit most frequently and they tend to visit the site every day. The results showed respondents giving even higher percentages than that reported by Whiteside (2008). A high percentage $(60 \%)$ of the respondents said they visited the site every day, compared to the $30 \%$ reported by Whiteside (2008). This could be influenced by the differences between the samples. For example, the sample for this research, Facebook users only, will be relatively computer literate. However, the majority of the respondents do not spend a great amount of time on the site per visit but most spend more than ten minutes on it per visit, only $23.12 \%$ spend less than ten minutes.

Hypothesis 2(a): Respondents will use social networking sites for social purposes

The results suggest that respondents will tend to use social networking sites mainly for social purposes. It seems that the most important reason why respondents use social networking sites is to talk to friends and family (77\% agreeing or disagreeing they use it to talk to close family or friends and $82 \%$ using it to talk to family or friends they rarely see) or track down old friends or family (66\%). This demonstrates the importance of Facebook as a communication tool. However, it is also used when no messages are sent, as many (52\%) will just look at 
others pages without leaving a message. Advertisers will have to take into account, with caution, that most people are using the site to socialise. The results suggest that it is not being used by members to talk to people they do not know. This may have implications for certain types of advertisement for example, an advertisement for meeting single people on-line could be misplaced on Facebook as the users are not interested in interacting with people they do not know off-line.

Respondents also largely disagreed that they used the site to look at campaigns (61\% agreeing or disagreeing). Advertisers trying to promote a campaign then face the challenge of grabbing the consumers' attention. Respondents may not use Facebook primarily to look at campaigns but this does not necessarily mean they will not switch motives, as Rogers \& Thorson (2000) suggested, whilst visiting the site, perhaps if they are bored and allowing themselves to browse different things. In order to achieve this the advertisement must standout.

The Spearman's Rho correlations suggested that the sample can be divided into two groups: Group 1- those who use it to socialise with people they already know and Group 2 those who do not to socialise with people they already know. Group 1 consists of those using it talk to close friends or family, friends or family they rarely see and to track down people they have lost touch with. Group 2 consists of those who use it to talk to friends of friends, listen to music or find out about bands, talk to people they do not know and look at campaigns/petitions. However, it must be remembered that those in group two are the minority.

The use of social networking sites for social purposes is further supported by the reasons why respondents chose Facebook over other social networking sites. The most important reason was because more of their friends were members ( $83 \%$ agreeing or strongly agreeing). The Spearman's Rho correlations also showed that those who chose it because more of their friends were members also tended to visit the site more frequently. As people go on the site to socialise and they have little interest in talking to people they do not know, there would be little point in joining a social networking site where their friends were not members. This has another implication for advertisers. They must keep up with the trends and fads within social networking, as Hawkes \& Gibbon (2008) suggested, because their target audience will simply follow where the majority of their friends appear to be.

Hypothesis 2(b): Respondents will not find banner advertisements placed on Facebook effective

Although the Internet was ranked the most frequently used medium, it is not ranked the most effective medium for advertising with only $32 \%$ of the respondents ranking it most effective, though this is not a completely negative figure. Television was ranked the most effective medium by $59 \%$ of the respondents. This contradicts Chaffey's (2007) claims that television advertising is a waste of time and the Internet is more effective because it is a lean forward medium. It is important to remember that there are many things a user can be looking at on the site. This is where clutter and other distractions become a problem to the on-line advertiser.

The results suggest that respondents do not find banner advertisements on Facebook effective. The biggest problem seems to be that respondents feel distracted by other content on the page ( $68 \%$ agreeing or strongly agreeing) and there are also problems with people feeling too bombarded by advertising clutter on the site and finding advertisements on the site a nuisance $(45 \%)$. The results showed an even higher percentage (46\%) 2 of respondents saying they felt bombarded by too much clutter and advertising than that of the UK study conducted by Jam/Myspace in early 2009, which was $26 \%$. This again may be due to sample differences by nationality. This supports the problem Dreze \& Hussher (1999) identified with banner advertisements sharing bandwidth with other content. It also means the large amount of time the users spend on-line and on Facebook could be detrimental to the effectiveness of the banner advertisement.

The large majority claim they do not tend to pay any attention to them (with $76 \%$ disagreeing of strongly disagreeing) or click on the link provided (61\% disagreeing or strongly disagreeing). This is a major problem for the advertiser because it will prove difficult to place an effective banner advertisement on Facebook if the target audience do not even pay them any attention. It is particularly a problem if we accept Chaffey's (2003) views that the purpose of a banner advertisement is to direct traffic to the website, as it would then seem banner advertisements are not serving their purpose.

A large number of the respondents (34\%) felt that advertisements on social networking sites were less effective than on other sites. This supports the claims that social networking sites bring additional problems to advertisers. The proposed benefit of social networking advertisements being more relevant, does not appear to be present as not many of the respondents (16\%) agreed that advertisements on their profile page tend to be more relevant to their needs. This supports Choi $\&$ Rifon's arguments that the content on social networking sites may be too general to be relevant enough to influence brand attitudes and purchase intent. However, a large percentage of the respondents (39\%) still think Facebook is a useful advertising tool. This suggests that the opportunity for effective advertising may be there but advertisers are failing to utilise the proposed benefits of relevancy. This ties in with Kennerdale's (2001) accusation that banner advertisements tend to be poorly targeted with little relevance to the user.

This does not provide any strong support for the view that the social use of the site will make it less effective. The respondents 
were asked directly if they thought advertisements on Facebook were even less effective than on other sites and the large majority were either neutral $(41 \%)$ or disagreed (25\%), though a fair number of the respondents agreed (34\%). This suggests the site being used for social purposes is therefore not the major problem it was made out to be in the literature, for example, by Tamler (2009) and James (2009).

\section{Hypothesis 3(a): Respondents will have a more positive attitude towards location specific advertisements on Facebook}

An important thing to note from the results is that the large majority ( $80 \%$ ) of the respondents include their location in their profile information, allowing advertisers to search and target these users based on location. The results suggest that respondents do have a positive attitude towards location specific advertisements on Facebook with the majority (64\%) agreeing that they are more effective than non-location specific advertisements. In what way do they find it effective? The majority (54\%) agree that location specific advertisements are more relevant to them. This contradicts Unni \& Harmon's (2007) argument that the perceived benefits of location specific advertisements are low, although it should be noted that their research regarding location was based on advertisements through mobile phones.

The Spearman's Rho correlation test also showed that those with positive attitudes towards advertisements placed on Facebook were more likely to have a positive attitude towards location specific advertisements. Likewise, those with negative attitudes towards banner advertisements on Facebook were more likely to hold negative opinions of location specific advertisements. This makes it questionable whether location specific advertisements can counteract negative consumer's attitudes, as those who already had a negative opinion of Facebook advertisements are likely to still have a negative opinion of a location specific advertisement. Unni \& Harmon (2007) suggested that well-tailored and targeted messages could counteract low perceptions of value. Perhaps being location specific is not enough. It should be teamed with other ways of tailoring the message to the target audience to be effective.

\section{Hypothesis 3(b): Respondents will be more responsive to location specific advertisements on Facebook}

The results suggest respondents are more responsive to location specific advertisements on Facebook but only at the lower levels of the On-line Consumer Response Hierarchy. It seems that location specific advertisements are more effective in terms of making users aware of the advertisement (41\% agreeing or strongly agreeing), read the content (42\% agreeing), remember seeing it (45\% agreeing) and remembering the content (41\%). The responses were fairly mixed with many remaining neutrals with regards to being more likely to click on the link provided
(39\% neutral) and reading the information on the brands website (33\% neutral). The results suggest that location specific advertisements are not more likely to increase purchase (with $50 \%$ disagreeing or strongly disagreeing).

An interesting result from the Spearman's Rho correlations, was between those who are more likely to click on a link provided by a location specific advertisement and those who think location specific advertisements stand out more. This was the only significant correlation found with those who are more likely to click on the link. This suggests that if the advertiser's aim is for users to click on the link, it is very important that they manage to make the advertisement standout.

\section{Conclusions and Implications}

The Internet is a highly used medium and Facebook is a highly used site on this medium. This is why it would be a great benefit to advertisers if they could communicate to their target audience effectively on-line. They may also want to consider a social networking site, such as Facebook, to host the advertisement.

If an advertiser does choose to place an advertisement on a site such as Facebook, they should be aware that people will mostly use it for social purposes and this can have implications for their advertising campaign. In particular, those who only tend to use it to talk to people they already know off-line can have different perceptions than those who do not use it for this purpose. This research suggests that the former will tend to have less favourable perceptions of advertisements on Facebook. Advertisers must also keep up with trends and fads in social networking. Users follow their friends meaning advertisers should find out where the 'hotspots' are for their target audience.

Advertisers should be aware that there are difficulties present making the Internet a less effective medium than one might hope for. This is a symptom of sharing bandwidth with other content. These problems are evident on Facebook. Users will often find banner advertisements placed on the site ineffective. They often feel distracted by other content on the page and by clutter. Advertisements on the site do not appear to stand out to users and the majority do not click on the links provided. Social networking offers the potential to send a more relevant tailored message to the target audience but this benefit is not being realised.

The research assessed whether a simple targeting base, geographical location, could make the advertisement standout more by increasing relevancy to the consumer. It seems that location specific advertisements do encourage more desirable attitudes. People think they are more effective and more relevant to them. However, they still do not seem to make the advertisement stand out more. Advertisers should be warned that those that already hold positive attitudes towards 
advertisements on Facebook are more likely to continue holding a positive attitude towards a location specific advertisement. Likewise, those that held a negative attitude towards advertisements on the site are more likely to continue holding negative attitudes if the advertisements are location specific. This does not mean all users holding negative perceptions of the advertisements will not recognise any value in location specific advertisements.

The increased perceptions of value created by making an advertisement location specific can make the users more responsive but only at certain levels of the on-line consumer response hierarchy. Advertisers may find location specific advertisements useful if their marketing objectives are based on increasing brand awareness and recall. The user is also more likely to read and remember the content of the advertisement, meaning very basic product/service information can be dispensed to users. However, location specific advertisements are not likely to be any more useful to advertisers if the objectives lie higher up the hierarchy. Also, if marketers rely on click through rates as a measurement of effectiveness, they are likely to achieve disappointing results.

\section{Limitations and Suggestions for Further Research}

Limited time and resources have put limitations on the research. The sample size, 176 respondents, is not an ideal size. This is especially the case as the sample covered a wide range of demographic groups, meaning many of the groups were too small to carry out any statistical tests upon. All that can be said for the sample is that it includes respondents from a wide range of demographic backgrounds, but there are not enough respondents within each group to make any decent generalizations regarding the differences between the groups. These differences would be of great interest to an international marketer. Further research could involve a larger more representative sample allowing statistical tests, such as the Chi Square test of independence, to be carried out and assess the significance of demographic groups to the responses given.

The results are also limited in that they reflect the opinions of Facebook users only. The results cannot be applied to other social networking sites. Further research could investigate other sites. On-line marketers can research sites that are 'hotspots' to their target audience at a given time. The results should be teamed with further research on the subjective features. The research did not take into account subconscious thought. This could limit the reliability of the results as it is very likely that the thought processes involved will involve some amount of subjective thought. Further research could involve laboratory experiments assessing eye movements in relation to different advertisements.

\section{References}

- Aitchison, J. (2006), World Advertising Research Centre, The Growth of Social Networking Websites,
http://www.warc.com/ArticleCenter/Default.asp?CTyp e=A\&AID=82876\&Tab=A Accessed 20/08/2009

- BBC News, 15 reasons why Facebook may be worth more than $\$ 15 \mathrm{bn}, \quad 25^{\text {th }}$ October 2007, http://news.bbc.co.uk/1/hi/technology/7061398.stm Accessed 22/03/09

- Belch, G. E. \& Belch, M. A. (2004) Advertising and Promotion: An Integrated Marketing Communications Perspective $6^{\text {th }}$ Ed., McGraw-Hill, New York

- Chaffey, D. (2007) E-Business and E-Commerce Management $3^{\text {rd }}$ Ed., Pearson Education Ltd, Essex

- Chaffey, D., Meyer, K., Johnston, K. \& Ellic-Chadwick, F. (2003) Internet Marketing, Strategy, Implementation and Practice $2^{\text {nd }}$ Ed., Pearson Education Ltd, Essex

- Choi, S. M. \& Rifon, N. J. (2002), Journal of Interactive Advertising, Antecedents and Consequences of Web Advertising Credibility: A Study of Consumer Response to Banner Ads, 3 (1), pp. 1-18 Crossref

- Cullen, J. B. \& Paraboteeah, K. P. (2005) Multinational Management: A Strategic Approach $3^{\text {rd }}$ Ed., Thomson/South-Western, Ohio

- Doyle, E, P. \& Stern, P. (2006) Marketing Management and Strategy $4^{\text {th }}$ Ed., Pearson Education Limited, Essex

- Dreze, X. \& Hussherr, F. (1999), Journal of Interactive Marketing, Internet Advertising: Is Anybody Watching? 17 (4), pp. 8-53. Crossref

- Economist.Com, Not Ye Olde Banners, 27 $7^{\text {th }}$ November 2008

http://www.economist.com/business/displaystory.cfm?sto ry_id=12684861 Accessed 22/03/09

- E-Marketer, Everybody Loves Social Networking, Except Some Advertisers, $\quad 1^{\text {th }} \quad$ March 2009 http://www.emarketer.com/Article.aspx?id=1006974 Accessed 22/03/09

- E-Marketer, Facebook Audience Matures, $25^{\text {th }}$ February 2009, http://www.emarketer.com/Article.aspx?R=1006930 Accessed 01/08/2009

- E-Marketer, Social Network Marketing Must Evolve, $17^{\text {th }}$ February 2009 http://www.emarketer.com/Article.aspx?id=1006927 Accessed 22/03/09 Facebook, www.facebook.com Accessed 20/08/2009

- Facebook, Facebook Ads, http://www.facebook.com/FacebookAds?v=app_714647

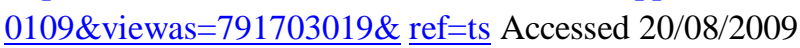

- Facebook, Facebook Advertising, http://www.facebook.com/FacebookAds?v=app_714647 $0109 \&$ viewas $=791703019 \&$ ref=ts\#/advertising $/$ ? $\mathrm{src}=\mathrm{pf}$. Accessed 20/08/2009.

- Hawkins, R. \& Gibbon, T. (2008) World Advertising 
Research Centre, Social Media Explained, http://www.warc.com/ArticleCenter/Default.asp?CType $=\mathrm{A} \& \mathrm{AID}=\mathrm{WORDSEARCH}$ 87645\&Tab=A Accessed 20/08/2009

- Ilfeld, J. S. \& Winer, R.S (2001) Journal of Advertising Research, Generating Web Site Traffic: An Empirical Analysis of Web Site Visitation, 42 (5), pp. 49-82 Crossref

- Interactive Advertising Bureau, Consumers Flood Social Networking Sites, Ad Support Struggles to Keep Pace, January 2009 , http://www.iab.net/insights_research/530422/1675/62775 2 . Accessed 01/08/09 Interactive Advertising Bureau, Social Network Marketing, February 2007

- http://www.iab.net/insights_research/530422/1675/62725 8/113392. Accessed 01/08/09.

- Interactive Advertising Bureau, January 2009: Social Networking Update, http://www.iab.net/insights_research/530422/1675/62775 2 Accessed 01/08/09

- James, L. (2009) World Advertising Research Centre, Should you Advertise on Social Networking Websites?

- http://www.warc.com/ArticleCenter/Default.asp?CType= $\underline{\mathrm{A} \& A I D=W O R D S E A R C H 88555 \& \mathrm{~T}} \underline{\mathrm{ab}=\mathrm{A}}$. Accessed 20/08/2009.

- Jobber, D. (2004) Principles and Practices of Marketing $4^{\text {th }}$ Ed., McGraw-Hill, Berkshire. Kennerdale, C. (2001) EContent, Banner advertising: still alive, but fundamentally flawed? 24(2), April, p. p56-57.

- Krishnamurphy, S. (2000) Management Marketing Chicago Ill, Deciphering the Internet Advertising Puzzle, 9 (3), pp.35-39.

- Machanda, P., Dube, J., Goh, K. Y. \& Chintagunta, P. K. (2006) Journal of Marketing Research, The Effect of Banner Advertising on Internet Purchasing, 43 (1), pp 98108. Crossref

- Moutinho, L., Goode, M. \& Davies, F. (1998) Quantitative Analysis in Marketing Management, John Wiley \& Sons Ltd, West Sussex.

- Neuborne, E. (2007) World Advertising Research Centre, Attract a Crowd http://www.warc.com/ArticleCenter/Default.asp?CType=

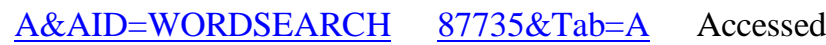
20/08/2009.

- Oz, E. (2002) Foundations of E-Commerce, Pearson Education Ltd, New Jersey Raskin, R. (2006) World Advertising Research Centre, Facebook Faces its Future

- http://www.warc.com/ArticleCenter/Default.asp?CType $=\mathrm{A} \& \mathrm{AID}=\mathrm{WORDSEARCH}$ 81502\&Tab=A . Accessed 20/08/2009.

- Rodgers, S. \& Thorson, E. (2000) Journal of Interactive Advertising, The Interactive Advertising Model: How Users Perceive and Process On-line Ads, 1 (1), pp.15-39. Crossref

- Saunders, M., Lewis, P. and Thornhill, A, (2003), Research
Methods for Business Students, $3^{\text {rd }}$ ed. (Essex: Pearson Education Limited).

- Sarantakos, S. (2007) A Toolkit for Quantitative Data Analysis, Palgrave MacMillan, Hampshire/New York. Crossref

- Sharma, A. \& Sheth, J. N. (2004) Journal of Business Research, Web-based Marketing: The Coming Revolution in Marketing Thought and Strategy, 57 (7), pp. 696-702. Crossref

- Tamler (2009), World Advertising Research Centre, Social Networking- Fancy Fad or Future Money Spinner.

- Tixier, M. (2005) International Business Review, Globalization and Localization of Contents: Evolution of Major Internet Sites Across Sectors of Industry, 47 (1), pp.15-48. Crossref

- Unni, R. \& Harmon, R. (2007) Journal of Interactive Advertising, Perceived Effectiveness of Push vs. Pull Mobile Location Based Advertising, 7 (2), n.pp. Crossref

- Vogt, C. \& Knapman. S (2008) World Advertising Research Centre, The Anatomy of Social Networks. http://www.warc.com/ArticleCenter/Default.asp?CType $=\mathrm{A} \& \mathrm{AID}=\mathrm{WORDSEARCH}$ 87631\&Tab=A Accessed 20/08/2009.

- Whiteside, S. (2008) World Advertising Research Centre, Social Networking in the UK: A Summary of an Ofcom Report into Attitudes Behaviours and Use http://www.warc.com/ArticleCenter/Default.asp?CType=A $\underline{\& A I D=W O R D S E A R C H} \quad \underline{87851 \& \mathrm{Tab}=\mathrm{A}}$ Accessed 20/08/2009

- Whiteside, S. (2008) World Advertising Research Centre, The International Communications Market: A Summary of Ofcom Research into Global Media Trends http://www.warc.com/ArticleCenter/Default.asp?CType $=\mathrm{A} \& \mathrm{AID}=\mathrm{WORDSEARCH} \quad$ 88824\&Tab=A Accessed 20/08/2009

- Wolfe, J. World Advertising Research Centre, Space Race

http://www.warc.com/ArticleCenter/Default.asp?CTyp $\underline{\mathrm{e}=\mathrm{A} \& \mathrm{AID}=\mathrm{WORDSEARCH}} \underline{82609 \& \mathrm{Tab}=\mathrm{A}}$. Accessed 20/08/2009

- Xie, T., Donthun, U, N., Lohtia, R. \& Osmonbekov, T. (2004) Journal of Interactive Advertising, Emotional Appeal and Incentive Offering in Banner Advertisements, 4 (2), n.pp. Crossref

- Yarmis, J. L. (2009) Business Week, How Facebook will Upend Advertising, May $27^{\text {th }}$ 